\title{
La coalición de la Alianza en Argentina (1999-2001): un caso entre bloques
}

\section{Beatriz María Silva Abelenda*}

\author{
Perfiles Latinoamericanos | Artículo \\ vol. 23 | núm. 45 | 2015 \\ pp. $31-58$
}

\begin{abstract}
Resumen
El artículo estudia la cohesión del bloque parlamentario de la Alianza en la Cámara Baja, a partir de la perspectiva del copatrocinio aplicada al primer caso de coalición formal, desde el retorno a la democracia en 1983. El trabajo analiza la performance legislativa del grupo parlamentario en función de las características constitutivas de los integrantes del bloque (composición federal, género y antecedentes parlamentarios), los espacios ocupados en el sistema de comisiones y su condición oficialista, para explorar las motivaciones que permitieron el copatrocinio logrado y las características que tuvo la práctica cooperante en una coalición de gobierno. En relación con el distrito y el partido como variables explicativas señaladas para el caso argentino, este trabajo identifica la experiencia de los titulares de las bancas, la distribución del bloque dentro de la Cámara y el curso político en los años 2000 y 2001 como fundamento del curso de la cooperación dentro del oficialismo.
\end{abstract}

\begin{abstract}
This paper studies the cohesion of the Alliance parliamentary bloc in the House, from the perspective of co-sponsorship applied to the first case of formal coalition since the return to democracy in 1983. The paper analyzes the performance of the ruling bloc according to the constitutive characteristics such as federal composition, gender and background parliamentarians, the space occupied in the Commission System and its status as the ruling bloc to explore the motivations and their characteristics in a coalition government. The district and the party identified as explanatory variables for the Argentine case, this paper highlights the experience of members, the distribution of the bloc in the House and the political course during 2000 and 2001 as the foundation of the course of cooperation within the ruling bloc.
\end{abstract}

Palabras clave: bloque legislativo, cohesión, Parlamento, copatrocinio, Poder Legislativo, Argentina, coalición.

Keywords: legislative bloc, cohesion, Parliament, co-sponsorship, Legislative Power, Argentina, coalition.

* Licenciada en Ciencia Política por la Universidad de Buenos Aires. Programa en Estadística Aplicada a las Ciencias Sociales (IDEs-Flacso Argentina, 2004). Centro de Graduados de la Universidad del Salvador. 


\section{Introducción ${ }^{1}$}

E

los regímenes presidencialistas latinoamericanos del Cono Sur, el Poder Ejecutivo conformado por una coalición registra antecedentes históricos en Chile, Uruguay y Brasil.

La República Argentina, por el contrario, cuenta con una escasa tradición en este sentido. En dicho país, la despolitización y pérdida de identidad partidaria impactaron en la conformación de los gobiernos en todos los niveles (tanto ejecutivos municipales y provinciales como en recambios parciales del Poder Legislativo), a tal punto que, a menos de veinte ańos en democracia, tales circunstancias impidieron que un partido por sí solo se encontrara en condiciones de presentarse a elecciones nacionales y competir por la Presidencia en 1999. Recordemos que hasta ese momento, el Poder Ejecutivo nacional, bajo el régimen democrático, ha sido ocupado por gobiernos de partido único: la Unión Cívica Radical (UCR), en su primera presidencia (1983-1989), y el Partido Justicialista (PJ), en sus dos presidencias posteriores (1989-1994 y 1995-1999). El estudio del Poder Legislativo, en este espacio histórico, destacó el aspecto disciplinario del grupo parlamentario y su comportamiento en relación con las acciones del Poder Ejecutivo (Jones, 2002; Mustapic, 2000).

La Alianza por el Trabajo, la Justicia y la Educación, integrada por la UCR y el Frente para un País Solidario (Frepaso) (1999-2001), constituyó el primer caso de coalición formal en Argentina desde el retorno a la democracia. El presente trabajo dedica su atención a la cohesión del bloque parlamentario oficialista en la Cámara de Diputados, con el propósito de aportar a la línea de investigación de los legislativos.

\section{Acerca del concepto cohesión}

Es pertinente, antes de continuar, proporcionar una nota acerca del significado asumido para la cohesión de grupo en este trabajo, ya que en ocasiones ha sido emparentado con el concepto de disciplina. En los últimos años, esta discusión ha sido planteada en el centro académico tanto norteamericano como euro-

1 Agradezco los comentarios y críticas de Manuel Sánchez de Dios (UCM), Carlos Moreira (Flacso Uruguay), Javier Fortín (UFM/Flacso Guatemala), así como las recomendaciones realizadas por los evaluadores anónimos a la versión preliminar de este escrito. Extiendo un reconocimiento personal a la Dirección de Información Parlamentaria de la Honorable Cámara de Diputados de la Nación y a todas las personas que han contribuido desinteresadamente en el desarrollo de este escrito. Los errores y omisiones son de mi exclusiva responsabilidad. 
peo con vistas a delimitar teóricamente el alcance de cada uno, sus líneas de análisis y variantes de medición. El primer autor que lo definió fue Ozbudun (1970), quien estableció que la cohesión resulta un atributo del acuerdo en el cual un grupo trabaja en común para lograr un objetivo. Posteriormente, la cohesión se analizó desde dos perspectivas diferenciadas: el comportamiento mismo del grupo y la racionalidad (Hazan, 2003). En este caso se destacan la socialización, la ideología y la historia del partido político, la solidaridad, las reglas informales, y la cultura partidaria, como las variables que permiten explicar la unidad de grupo.

Los estudios posteriores enfatizaron la idea de unidad en virtud del trabajo común por el bien común de la bancada o por compartir coincidencias ideológicas, preferenciales o valores (Bowle, Farrell, y Katz, 1999; Casar, 2000; Cox, y Morgenstern, 2002; Owens, 2003; Hawkins, y Morgenstern, 2003; González Tule, 2007). Desde la perspectiva del estudio de los actores de veto, Tsebelis (1998) definió la similitud de posiciones políticas dentro de un partido entre actores requeridos para lograr un acuerdo (actores de veto) y respecto de un tema determinado.

En la última década ha cobrado vigencia una nueva línea de estudio explicativa para el concepto, ligada con la teoría de la acción colectiva: la teoría de redes de patrocinio y copatrocinio de la legislación. La red formada a través de las acciones cooperantes destaca dos aspectos relevantes: la similitud de las preferencias políticas y la intensidad de la preferencia sobre determinadas áreas de política (Fowler, 2006). El valor del copatrocinio es definirse como una estrategia voluntaria en el ámbito de la relación social legislativa que se diferencia de una votación, acción donde los legisladores están obligados a emitir votos sobre proyectos (Bernhard y Sulkin, 2009).

El análisis de la colaboración y el trabajo conjunto entre legisladores permite sostener que la cohesión, en el marco de este trabajo, en el ámbito politológico y a diferencia de la disciplina, explica el grado de acercamiento entre legisladores, las motivaciones que estimulan la integración de los miembros dentro y entre bloques, y su pertenencia a un grupo parlamentario, en función de su participación en la tarea legislativa.

\section{Antecedentes de estudio}

Desde 1983, la continuidad democrática ha permitido estudiar la cooperación legislativa en la Cámara de Diputados nacional desde dos perspectivas: a) el estudio de las preferencias individuales de los legisladores, y $b$ ) las conexiones sociales que se desarrollan dentro del Congreso. 
Eduardo Alemán (2009) ha estudiado las preferencias de los legisladores en el Congreso argentino (1983-2002) y norteamericano (1973-2000), con base en el copatrocinio, a fin de abordar el tema desde una nueva dimensión diferenciada del voto nominal.

En la línea de trabajo relacionada con la cooperación conjunta, se ubican Calvo y Leiras (2011). Ambos autores concentran su atención en la Cámara de Diputados local (1984-2007). El esfuerzo colaborativo se mide a través de la cosuscripción de proyectos entre legisladores pertenecientes a un mismo bloque y legisladores electos en el mismo distrito electoral de origen. El presente trabajo demuestra que, en el devenir democrático, la membresía partidaria entre legisladores del mismo bloque y la pertenencia al mismo distrito explican el grado de colaboración en la Cámara Baja. La nacionalización legislativa tiene lugar cuando la colaboración en las iniciativas se gesta entre legisladores del mismo bloque, electos en diferentes distritos. De acuerdo con las características del sistema partidario argentino, los autores tipifican el grado de nacionalización electoral (de acuerdo con el alcance territorial de la fuerza política) y legislativa, en los cuales, y para los propósitos de este artículo, la Unión Cívica Radical denota un alto grado de nacionalización mutua, y el Frepaso, una baja nacionalización electoral y una alta nacionalización legislativa.

Alemán y Calvo (2010), en clave comparada, estudian los congresos chileno (2002-2006) y argentino (1997-1999). Aquí la cooperación se encuentra estimulada por la pertenencia partidaria, los vínculos territoriales y la comisión parlamentaria, donde tiene inicio la propuesta, teniendo en cuenta de qué manera influye la experiencia o especialización en el tema a legislar.

Los resultados de la investigación reflejan que, en la composición de redes, las variables propuestas se contrastan positivamente. En este marco, el grado de cohesión partidista se ve favorecido por el acercamiento entre diputados copartidarios y pertenecientes a la misma región, aunque en distinta forma de acuerdo al país. En Argentina, la transversalidad de los lazos pone de relieve la división entre los dos partidos principales y contendientes por la presidencia, los peronistas, por un lado, y la UCR, por el otro, ambos típicamente bien definidos centristas catch-all. Téngase aquí en cuenta que el trabajo ubicó un periodo de alta competencia política antes de la conformación de la Alianza (1999-2001). En Chile, en cambio, se diferencian los partidos que se alinean con la premisa de alta colaboración intrapartidaria: Partido Socialista, Unión Democrática Independiente; en segundo lugar, aquellos que cuentan con una cohesión interna menor: Renovación Nacional y Partido para la Democracia, donde destaca el Partido Radical Socialista Democrático como un caso que culturalmente es propenso a colaborar con otros miembros de la coalición en mayor medida que con sus propios partidarios. 
Los antecedentes expuestos y los aportes para el caso argentino resultan el marco y punto de partida para el desarrollo de este escrito. La coalición de gobierno, a diferencia de un gobierno de partido, tiene una composición de grupo compleja y heterogénea, ya que su bloque es, a la vez, una suma de fracciones. En efecto, el estudio de Calvo y Leiras (2011) identifican la membresía y la provincia como fundamento para la colaboración. Sin embargo, la medición conjunta entre ambas variables para el periodo de la Alianza (1999-2001) resultó el menos significativo en la medición general.

En Argentina, el gobierno de partido ha sido la regla general y los resultados de las investigaciones legislativas están referidos a un bloque de partido. Si la Coalición se presenta como un caso atípico: ¿los resultados obtenidos le pueden ser aplicados?

En función del problema planteado, los objetivos propuestos aquí buscarán identificar las motivaciones que permiten el copatrocinio y explorarán las características de la práctica cooperante en el caso de estudio. En este marco, se postulan dos hipótesis:

H1: Las características constitutivas de los integrantes del bloque y los espacios ocupados en el sistema de comisiones, en una coalición de gobierno, tienen un impacto directo en la cohesión del grupo legislativo.

Los indicadores establecidos para definir las características constitutivas son la provincia de origen, los años de experiencia legislativa, y el género del legislador o legisladora. Los espacios ocupados por el bloque se refieren a la distribución del bloque en el sistema de comisiones (integrantes de fracción por comisión y jefaturas). Las firmas incluidas en la presentación de proyectos sancionados permiten verificar el impacto que la composición de grupo tiene en el resultado legislativo.

El patrón común en el copatrocinio en la Argentina ha identificado como principales hallazgos al partido y al distrito. Por tratarse, en este caso, de un bloque oficialista, interesa conocer si su condición de oficialismo y los sucesos de gobierno inciden en la práctica cooperante. De esta forma, se suma una segunda hipótesis:

H2: En un bloque legislativo oficialista, los sucesos políticos en el gobierno influyen en el curso de las prácticas cooperantes de sus integrantes.

Los sucesos influyentes en la unidad de bloque fueron seleccionados de la agenda de los medios periodísticos y los debates sostenidos en el recinto, los 
cuales constituyen el indicador para el curso político del gobierno. El registro de firmas en leyes e iniciativas durante los periodos legislativos 118 y 119 será observado en función de dichos sucesos, para verificar la influencia sobre las prácticas cooperantes de los integrantes de las fracciones dentro y fuera del bloque oficial. Las fuentes incluidas son: a) Dirección de Información Parlamentaria, b) Información periodística, c) Diario de Sesiones (periodos 118 y 119), y d) Entrevistas a funcionarios del gobierno.

La base de datos conformada para el seguimiento del registro de firmas se compone de 101 leyes sancionadas y 130 iniciativas inconclusas, distribuidas como lo muestra el cuadro 1.

Cuadro 1. Producción parlamentaria por periodo y origen de firmas

\begin{tabular}{|c|c|c|c|c|}
\hline \multirow{2}{*}{$\begin{array}{l}\text { Periodo } \\
\text { parlamentario }\end{array}$} & \multirow{2}{*}{ Total leyes $^{a}$} & \multirow{2}{*}{$\begin{array}{l}\text { Poder } \\
\text { Ejecutivo }\end{array}$} & \multicolumn{2}{|c|}{ Honorable Cámara de Diputados } \\
\hline & & & $\begin{array}{c}\text { Leyes } \\
\text { sancionadas }\end{array}$ & Iniciativas inconclusas ${ }^{b}$ \\
\hline $117(1999)$ & 6 & 6 & - & - \\
\hline $118(2000)$ & 72 & 11 & 61 & 56 \\
\hline $119(2001)$ & 47 & 7 & 40 & 74 \\
\hline Total & 125 & 24 & 101 & 130 \\
\hline \multicolumn{5}{|c|}{${ }^{\mathrm{a}}$ Del total de 170 leyes sancionadas, se desestiman las leyes de forma (45). } \\
\hline \multicolumn{5}{|c|}{$\begin{array}{l}{ }^{b} \text { La selección incluye los proyectos que lograron discusión en el Pleno o alcanzaron la media sanción durante el peri } \\
\text { do de estudio. }\end{array}$} \\
\hline \multicolumn{5}{|c|}{ Fuente: Elaboración propia con base en datos de la Honorable Cámara de Diputados (www.diputados.gov.ar). } \\
\hline
\end{tabular}

Lo expuesto en la introducción se desarrolla en tres apartados: la presentación de la Alianza como bloque político, desde la composición de grupo y el sistema de comisiones; las hipótesis de trabajo I y II, y las lecciones aprendidas para el caso de estudio.

\section{Los inicios de la Alianza por el Trabajo, la Justicia y la Educación}

La coalición electoral fue integrada por la Unión Cívica Radical (UCR) y el Frente País Solidario (Frepaso). Ambos partidos políticos mantenían percepciones de las alianzas muy diferentes entre sí, que resulta interesante señalar.

La UCR, partido constituido en 1891, registró en su larga trayectoria únicamente dos casos de coalición electoral (1943 y 1946). El Frepaso, por su parte, tuvo sus orígenes en 1990 y, dentro del Parlamento, en el bloque Movimiento Peronista integrado por el "grupo de los ocho" (grupo disidente del bloque justicialista), el cual, para poder proyectarse políticamente, encuentra coincidencia en el sector no oficialista del PJ y dos sectores de la UCR: la línea de Federico 
Storani (Provincia de Buenos Aires) y los seguidores de Rodolfo Terragno (Capital Federal).

La política de alianzas entre ambas fuerzas políticas fue condición constitutiva imprescindible para el Frepaso, mientras que para la UCR, con una estructura centenaria, se volvió necesaria en la medida en que el partido no pudiera lograr el acceso a la Presidencia sin un socio electoral. La incorporación de un sector del pu a la Alianza resultó estratégica, ya que así como la pata peronista permitiría un acercamiento del bloque oficialista con el PJ, los opositores procuraban contar con una pata frepasista que permitiera un canal de diálogo desde el pJ en el grupo oficialista de la Cámara (Ollier, 2001: 89).

\section{El bloque oficial de la Alianza (1999-2001)}

El grupo legislativo que asumió funciones el 10 de diciembre de 1999 (sesión preparatoria núm. 39) quedó conformado por 34 diputados frepasistas y 91 diputados radicales (total: 125 representantes). En el marco de esta observación, se busca analizar el trabajo conjunto, a partir de lo que distingue al diputado dentro de su grupo, y de la manera en que influye la distribución de los integrantes de su grupo en la Cámara, y su acción colaborativa. Por esta razón, se desagrega en dos niveles: dentro del bloque y en el marco de su inserción en el sistema de bloques.

El primer nivel se refiere a la composición de grupo según provincia de origen, experiencia y género de sus integrantes. En este sentido, es necesario considerar una característica del Parlamento argentino: el esquema de renovaciones bienales. La Presidencia de la nación se elige cada cuatro años con posibilidad de reelección por una sola vez. Cada presidencia es acompañada por un bloque de diputados oficialistas, que supone un respaldo inicial a su gestión en la Cámara de Representantes. Dicho bloque se encuentra integrado por legisladores provenientes de la gestión anterior, junto con legisladores que se incorporan al mismo tiempo que el Ejecutivo. Este mismo grupo, al tercer año, vuelve a renovarse parcialmente. Es entonces que estos legisladores en el cargo pueden renovar su banca, o bien, dar paso a otros nuevos. Así, los bloques políticos en Argentina no son grupos que se constituyen en su totalidad al iniciar un nuevo ejercicio y que perduren hasta el final del mandato presidencial; más bien, representan cambios y continuidades al mismo tiempo.

El segundo nivel presenta la inserción del bloque en el sistema institucional de la Cámara, a partir de la asignación de las comisiones y las jefaturas en favor del oficialismo, en este caso, propio de la asignación del bloque que ingresó en 1999. 
La distribución federal expuesta del grupo parlamentario tuvo en cuenta dos aspectos: a) el bloque compuesto por fracciones políticas que expresaría el (des)equilibrio de poder entre partidos (en su condición de primera minoría de la Cámara Baja), y b) el mapa federal de las gobernaciones provinciales de acuerdo con el resultado de las elecciones de 1999, el cual impacta sobre el grado de libertad del legislador.

El primer acuerdo electoral de fracciones en 1997 denotó un balance positivo al conseguir el primer grupo parlamentario de 62 diputados, los cuales constituyeron prácticamente el 50\% del total del bloque que ingresó en 1999, con alta influencia de Capital Federal y la Provincia de Buenos Aires en los acuerdos. Al inicio del periodo parlamentario 118, el bloque oficial se integró con 29 diputados provenientes de distritos donde el Frepaso no obtuvo representación. El funcionamiento de la Alianza y del bloque parlamentario en la Cámara, entonces, dependería del nivel de fusión y aceptación que encontrase dentro de la estructura radical.

La distribución del bloque oficial por distrito y fracción demuestra que su conformación agrupó aliancistas con frepasistas y radicales que provenían de distritos donde no se lograron acuerdos electorales.

En su condición de primera minoría, el cambio y la continuidad dentro del bloque tuvo lugar entre las elecciones legislativas de 1997 y 1999.

El núcleo originario y contestatario de la Alianza, por afinidad de criterios políticos y de pertenencia al distrito, tuvo lugar en la Capital Federal y la Provincia de Buenos Aires. El capital propio de votos para el gobierno de la UCR se alcanzó con las bancas aliancistas del interior del país, alineadas en el Grupo Federal (línea interna radical, gestada durante sus años de oposición).

Si el mapa federal del bloque se relaciona con la distribución de los resultados obtenidos por los partidos políticos para ocupar los ejecutivos provinciales de aquel año, se puede intuir un alto grado de libertad en las decisiones de los diputados respecto de las líneas directrices de la gobernación y el partido en su distrito de origen. Así, la Alianza fue sólo favorecida con tres ejecutivos provinciales, de los seis casos que se presentaron conjuntamente el 24 de octubre de 1999 (día de elecciones nacionales). Para la Alianza, la principal derrota estuvo representada en la provincia de Buenos Aires, definida históricamente como la madre de todas las batallas, pues influye en los gobiernos presidenciales no sólo en el nivel de gobernabilidad nacional sino en su capacidad de confrontación con la oposición. 
Gráfica 1. Distribución comparativa de bancas del bloque aliancista por fracción (UCR-FREPASO). Elecciones legislativas 1997-1999
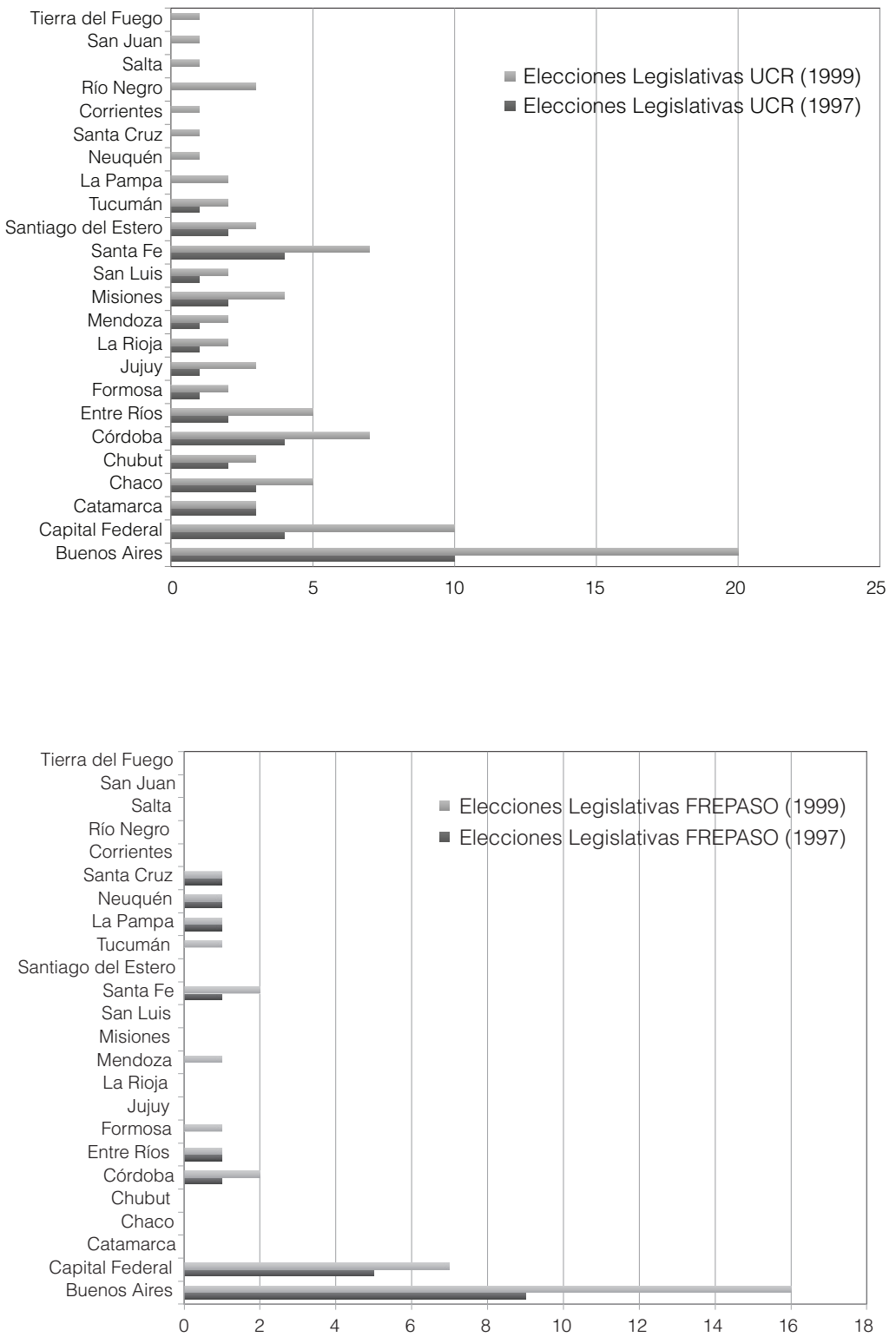

Fuente: Elaboración propia con base en información de la Dirección de Información Parlamentaria (2005).

Perfiles Latinoamericanos | vol. 23, núm. 45, enero-junio de 2015 | Flacso México Beatriz María Silva Abelenda | La coalición de la Alianza en Argentina (1999-2001): un caso entre bloques | pp. 31-58 
En este contexto, la coalición aliancista aumentó el (des)equilibrio de fuerzas entre los dos socios de la coalición. En el Frepaso, ganar la provincia junto con la Capital Federal hubiera constituido un fuerte contrapeso a las ventajas estructurales del radicalismo. Y al presidente radical De la Rúa, el no haber obtenido la gobernación de la provincia dentro de sus cuadros, lo expuso a las demandas y exigencias de sus propios partidarios, en la medida en que el Frepaso no aumentaba sus espacios federales de poder.

Los resultados finales indican que la coalición contó con ochenta legisladores provenientes de provincias que quedaron en manos de la oposición. De esto podría deducirse que la influencia del partido a nivel nacional resultaría mayor en el distrito partidario provincial (que no en todos los casos acompanó la línea oficialista), y en el área legislativa, una mayor independencia de sus legisladores (De Luca, Jones y Tula, 2000).

\section{Los antecedentes parlamentarios y el género en el bloque oficial}

El siguiente aspecto a considerar se relaciona con el desarrollo del trabajo parlamentario: los antecedentes en la Cámara de los diputados electos que integran el bloque oficialista. El Parlamento argentino guarda históricamente una baja tasa de recambio para el retorno de los legisladores a la Cámara (tendencia que se acentuó a partir de la presidencia de Alfonsín, en 1983), alineado a la tesis de la condición de amateur dentro del Parlamento (Jones, Saiegh, Spiller, y Tommasi, 2000).

La tasa de renovación parlamentaria es un indicador que ha aportado la información del cuadro 2.

Cuadro 2. Renovación parlamentaria del bloque oficialista (1999-2001)

\begin{tabular}{|c|c|c|c|c|c|c|}
\hline Bloque aliancista & Total diputados & $\begin{array}{c}1^{\circ} \text { periodo parla- } \\
\text { mentario }\end{array}$ & $\begin{array}{l}1 \text { periodo } \\
\text { anterior }\end{array}$ & $\begin{array}{l}2 \text { periodos } \\
\text { anteriores }\end{array}$ & $\begin{array}{l}3 \text { periodos } \\
\text { anteriores }\end{array}$ & $\begin{array}{l}4 \text { periodos } \\
\text { anteriores }\end{array}$ \\
\hline Fracción 1997 & 62 & 50 & 10 & 2 & - & - \\
\hline UCR & 42 & 33 & 8 & 1 & - & - \\
\hline FREPASO & 20 & 17 & 2 & 1 & - & - \\
\hline Fracción 1999 & 63 & 44 & 15 & 2 & 1 & 1 \\
\hline UCR & 52 & 42 & 7 & 1 & 1 & 1 \\
\hline FREPASO & 11 & 2 & 8 & 1 & - & - \\
\hline Totales & 125 & $94^{*}$ & 25 & 4 & 1 & 1 \\
\hline
\end{tabular}

* El cuadro desagrega información entre fracciones, pero ésta no se acumula. Téngase en cuenta que los diputados que ingresaron a la Cámara en la renovación legislativa del año 1997, cumplieron su mandato hasta el año 2001. En cambio, los diputados que ingresaron con la presidencia aliancista, ocuparon la banca hasta 2003, de manera tal que ningún diputado que integraba la primera fracción integró la segunda por renovación.

Fuente: Dirección de Información Parlamentaria (2005). 
El cuadro 2 refleja los antecedentes en cuanto al paso por la Cámara Baja de sus integrantes por fracción y fuerza política. Si bien la integración de un bloque anterior a esta presidencia no supone per se un grado de conocimiento mayor de los canales del trabajo parlamentario, los diputados que tienen al menos un periodo anterior - que supone la experiencia del recambio legislativo junto con el cambio de administración- cuentan con ventajas respecto de un diputado que ingresa por primera vez y un factor de poder dentro del grupo legislativo.

En relación con el género en la conformación parlamentaria, 38 mujeres "representaron" el 30\% del bloque; compuesto según la ley de cupos vigente en Argentina desde 1995. Se destaca un mayor número de legisladoras frentistas que radicales. Si bien, en la práctica, en ninguna de las dos fuerzas políticas la figura femenina ocupó el liderazgo de primera línea, el Frente tuvo una incidencia femenina mayor en la línea parlamentaria que el radicalismo, donde la mujer no ha tenido en su historia dirigentes de género que encabecen líneas partidarias antes de la coalición de 1999. Sociológicamente, 50\% de la representación femenina concentró en las ciudades la mayor representación y, en particular, en los dos distritos centrales para el gobierno, con antecedentes en legislación, a diferencia de muchos de sus compañeros de banca; sin embargo, esta condición no tuvo avances significativos hacia espacios o cargos de poder dentro del bloque político.

Hasta aquí, el bloque ha sido visto por determinadas características de sus integrantes. A continuación, se presenta su integración al sistema de comisiones de la Cámara.

\section{El bloque en el sistema de comisiones permanentes}

La presidencia de la Cámara, las jefaturas de comisión a cargo del oficialismo y la designación de los integrantes sin jerarquía en las comisiones parlamentarias resultan ser puntos neurálgicos para comprender el impacto del bloque en la tarea conjunta.

En el caso de estudio, la distribución del bloque oficialista guardó relación con su primera condición de minoría, sin embargo, la principal peculiaridad tuvo que ver con la distribución de ambas fracciones en todo el sistema de comisiones. Mientras que el radicalismo designó a sus integrantes (con o sin cargo de jefatura) en comisiones asignadas al partido político, los integrantes del Frepaso quedaron dispersos en toda la Cámara tanto en comisiones oficialistas como opositoras, sin relación con la jefatura a cargo de la comisión.

De esta forma, los radicales quedaron agrupados en las mismas áreas de trabajo, con un número de comisiones menor por diputado en relación con la fracción frepasista, la cual recibió individualmente un mayor número de 
comisiones; es decir, quedaron en desventaja respecto de las posibilidades de éxito legislativo del Frepaso.

En el esquema de cargos de jefatura se puede observar la relación de fuerzas del oficialismo pero, al mismo tiempo, dentro del oficialismo, a partir de la presidencia de la Cámara, la jefatura de bloque y las jefaturas de comisión, no sólo por constituir cargos de dirección sino por el poder de agenda que condiciona el éxito de los proyectos impulsados en la Cámara. La estructura política de cargos dentro del bloque fue repartida, en proporción y de acuerdo con su condición de coalición, entre frepasistas y radicales. Mientras tanto, la presidencia del bloque aliancista quedó a cargo de Darío Alessandro (Frepaso) y Rafael Pascual (UCR) ocupó la presidencia de la Cámara.

El gobierno electo consiguió la jefatura de 28 comisiones (del total de 44). Si bien este reparto se relacionó con su condición de oficialismo, la ajustada mayoría de bancas en favor del gobierno electo (125 legisladores) tuvo un impacto negativo en la conformación de los integrantes de las comisiones. Únicamente en doce casos adjudicados al oficialismo, aquéllas quedaron conformadas con mayoría propia (de las cuales once tuvieron más de $50 \%$ de diputados oficialistas y sólo fue en el caso de Derechos Humanos y Garantías, a cargo de Alfredo Bravo, donde oficialismo y oposición contaron con la misma cantidad de integrantes). Las comisiones restantes a cargo del oficialismo (16) — casos como Juicio Político, Legislación General y Presupuesto y Hacienda - se conformaron con mayoría opositora.

La gráfica 2 presenta la asignación general para toda la Cámara, con la participación del oficialismo como bloque.

Esta distribución muestra que entre diputados oficialistas y opositores no se respetó el mapa político de la Cámara, ya que 29 comisiones del total del sistema de comisiones de dicha institución tuvieron mayoría opositora, aun cuando su jefatura quedara a cargo del oficialismo. Si la asignación se evalúa en términos de fuerza dentro del oficialismo, $50 \%$ de las presidencias quedó en manos de legisladores pertenecientes al núcleo originario de la coalición.

Las características expuestas reflejan los propósitos de cada fracción en respuesta a sus intereses partidarios y al grado de apoyo esperado por parte del gobierno. Para los frepasistas, la presencia de dirigentes de primera línea en la Cámara Baja resultó el único espacio visible y real en el esquema de poderes de gobierno. Para los radicales, el objetivo principal fue sostener el programa de gobierno a través del nombramiento de comisiones estratégicas a su cargo y designar dirigentes partidarios con experiencia legislativa con la finalidad de afectarlos en la negociación y en el acuerdo entre legisladores tanto oficialistas como opositores. Esta decisión selló al Congreso como el escenario de las partidas políticas dentro del oficialismo. 


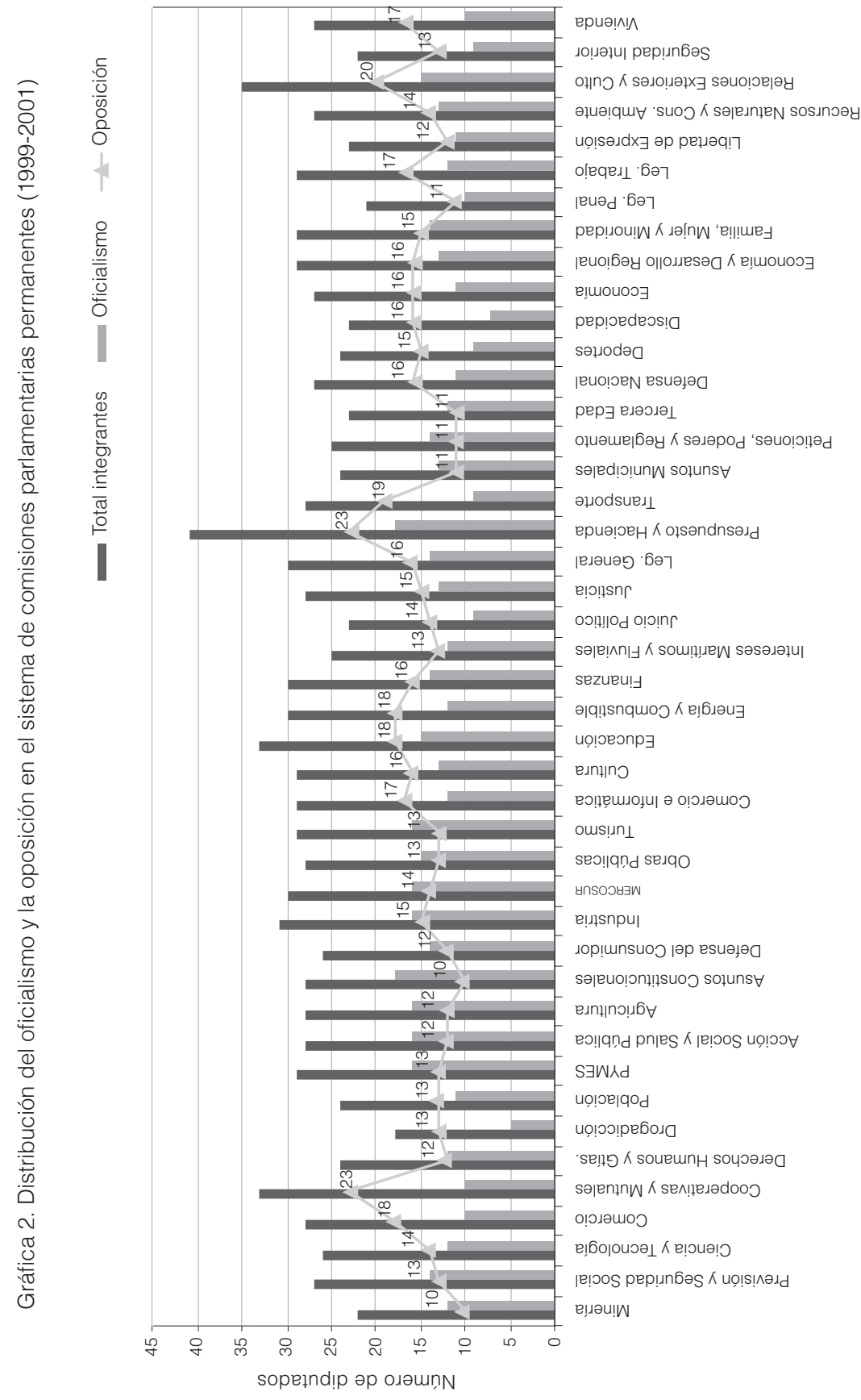


En este apartado se ha presentado el bloque oficial en dos niveles: 1) a partir de determinadas características que componen al grupo, y 2) su lugar en el sistema de bloques. La influencia de ambos niveles en la acción colaborativa refleja un marco desfavorable para la cohesión de grupo, de acuerdo con las ideas expuestas por Ostrom y Walker (1997), ya que los objetivos políticos expuestos y la dispersión del socio menor en el espacio legislativo tendrían un costo alto para el trabajo conjunto y la cooperación en el tiempo.

\section{La cohesión en la Alianza}

Este apartado se dedica a la observación y el análisis de la cohesión de bloque en función de las dos hipótesis de trabajo propuestas más arriba.

De acuerdo con la composición de grupo y su lugar en el esquema de comisiones, interesa saber qué impacto se observa en el éxito parlamentario alcanzado (101 leyes sancionadas) en los dos años de gestión, el cual mantuvo su condición oficialista hasta la renuncia de De la Rúa el 20 de diciembre de 2001, momento en que el gobierno pasó a manos del Partido Justicialista. Durante ese lapso, el bloque oficial inicial de 125 diputados tuvo dos rupturas formales durante 2001, en una de éstas nueve diputados conformaron dos bloques disidentes: Argentinos por una República de Iguales (con dos diputados radicales y tres socialistas) y Frente para el Cambio (con cuatro diputados frepasistas).

El bloque oficialista se realineó en un sector afín al Poder Ejecutivo y en otro crítico a la conducción del gobierno donde se distinguieron integrantes de ambas fracciones.

\section{H1. El grupo legislativo y el éxito parlamentario}

La producción legislativa de la Cámara fue mayor en el primer periodo (en el segundo se vio afectada por las elecciones legislativas de renovación de bancas). Al comparar la integración de firmas de los legisladores, entre los proyectos concluidos exitosamente y las iniciativas parlamentarias, la distribución entre ambos grupos es pareja. Este primer indicador de trabajo grupal es constante y se registra en todo el periodo de estudio como favorable a la cohesión de bloque. La construcción del consenso estuvo relacionada con el tema legislativo y el nivel de conflicto hacia su tratamiento en el Parlamento. El área social (discapacidad, educación, cultura, y asistencia social) y los intereses federales (aduaneros, agrícolas o mineros) explican el éxito parlamentario. 
En el apartado que sigue se desagregan los resultados de la producción de leyes promulgadas por provincia, años en la Cámara y género legislativo en relación con la primera hipótesis.

\section{La sanción de iniciativas por provincia}

La producción se distingue en un grupo reducido de provincias para ambos periodos.

Gráfica 3. Producción legislativa oficialista por distrito y periodo parlamentario (118 y 119).

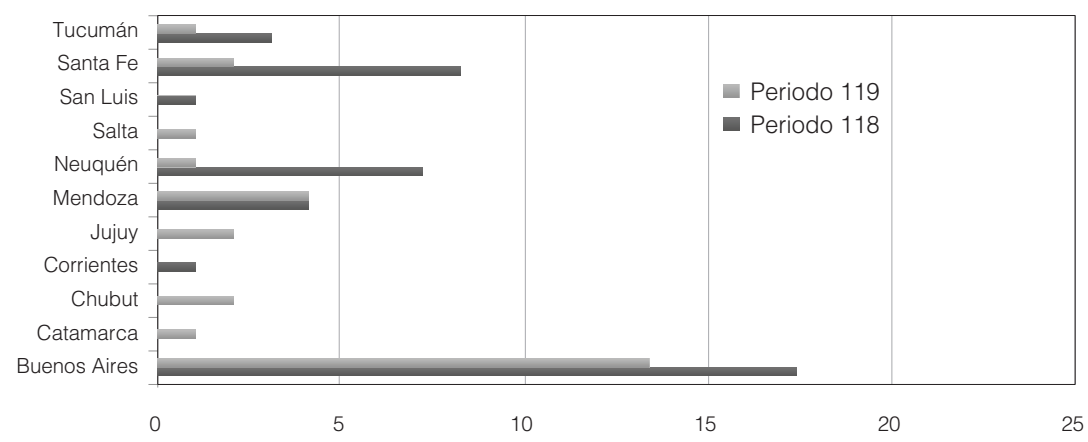

Fuente: Elaboración propia con base en datos de la Honorable Cámara de Diputados (www.diputados.gov.ar).

El segundo año parlamentario denota un avance de las provincias gobernadas por el Partido Justicialista y de aquellas donde la UCR obtuvo representación sin alianza con el Frepaso, confirmando la premisa acerca del alto grado de libertad esperado para gran parte del bloque, proveniente de distritos a cargo de la oposición.

La provincia de Buenos Aires suma proyectos impulsados por legisladores originarios del mismo distrito, con antecedentes en la Cámara y con una significativa participación de género.

A la vista de los focos de conflicto, de las disidencias y de las rupturas de bloque, parece paradójico que dicho distrito haya resultado el más productivo en términos de leyes. Así, la evidencia muestra que las características que acompañaron la labor parlamentaria no se relacionaron con la pertenencia al bloque, sino con el distrito de origen. De acuerdo con las notas teóricas, el número de 
integrantes del grupo parlamentario es un aspecto favorable a la cohesión, ya que los referentes y centros de influencia en todas sus formas ofician de mediadores y canales de diálogo. En efecto, los 33 proyectos impulsados por legisladores de la provincia de Buenos Aires tuvieron en su mayoría cofirmantes locales (antes y después de las rupturas de bloque) lo que refleja un interés de distrito y una agenda común entre los numerosos bonaerenses.

Esta influencia incluye la participación de los bloques disidentes con el oficialismo aliancista, ya que tanto en el bloque de Argentinos por una República de Iguales (ARI) como en el Frente para el Cambio (FC), los diputados provenían de estos estados provinciales (excepto Elisa Carrió, electa por la provincia del Chaco). Así como las rupturas de bloque demuestran un alejamiento del poder político, denotan a la vez una zona de cooperación favorable a la tarea legislativa, donde los representantes se relacionan nuevamente con el distrito de origen en temas propios de la provincia.

La zona de cooperación abarcó también a los diputados disidentes congregados en el FC y en el ARI, entre pares. Los resultados reflejan que entre los diputados disidentes, la línea de trabajo distrital resultó el puente para el trabajo conjunto. El mínimo margen de continuidad entre los radicales y la disidencia está relacionado con el peso del distrito en los temas que dieron lugar a las iniciativas conjuntas en capital y provincia de Buenos Aires. Un caso particular dentro del radicalismo fue la diputada Margarita Stolbizer, quien, habiéndose quedado en el bloque, acompañó y presentó la mayor cantidad de proyectos conjuntos con los diputados disidentes en relación con su distrito, en temas de legislación general y penal, lo que permitió entrever la tensión del bloque y su distanciamiento como oficialista.

\section{Los antecedentes parlamentarios y el género}

La productividad legislativa inclina los resultados en favor de los representantes con antecedentes parlamentarios. En efecto, de los 69 legisladores que consiguieron promulgar sus iniciativas, 47 contaban con experiencia anterior. En primera instancia, los legisladores con años en la Cámara explican el éxito parlamentario. Pero el cruce entre la participación de legisladores con experiencia parlamentaria y los diputados noveles permite otras conclusiones para el periodo: la presentación de iniciativas exitosas en forma conjunta refleja que en realidad los diputados con experiencia legislativa diseminaron su presencia en toda la producción parlamentaria, y la tendencia muestra que, a medida que el gobierno aumentó su tiempo en el ejercicio y a pesar de los vaivenes políticos, los diputados con experiencia mantuvieron su participación en los proyectos. 
Gráfica 4. Producción parlamentaria por experiencia legislativa.

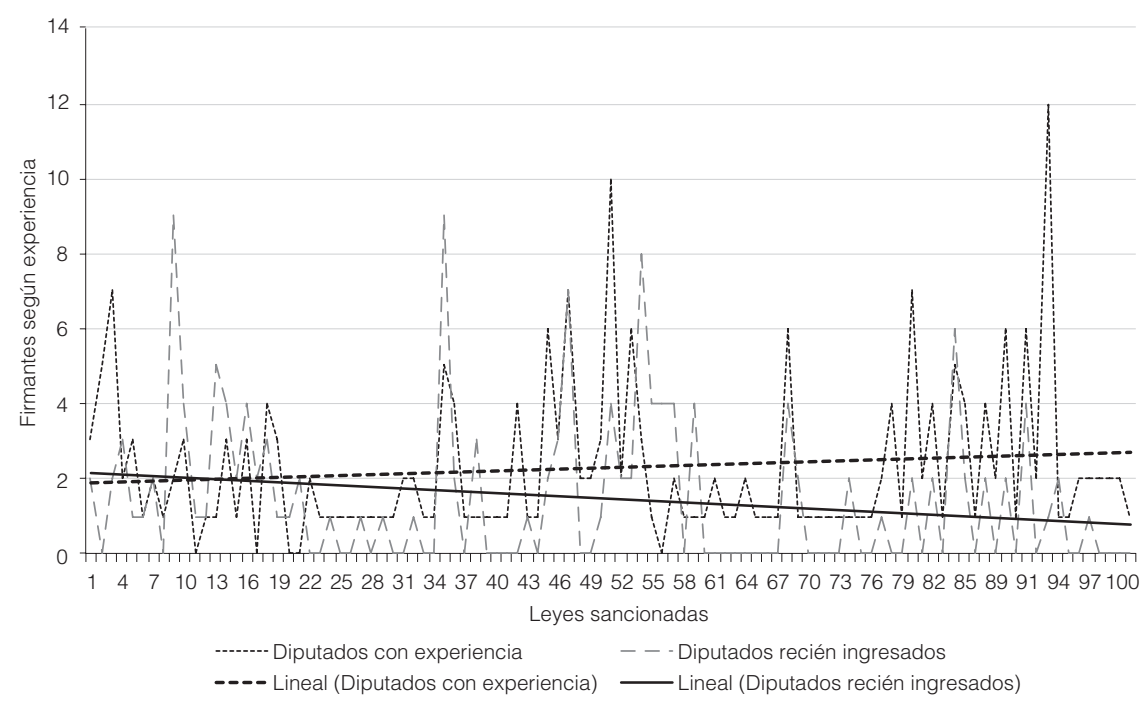

Las leyes están ordenadas en orden cronológico, lo que facilita la observación de la evolución de las firmas. En ambos grupos, se agrega una línea de tendencia lineal que abarca ambos periodos parlamentarios. Fuente: Elaboración propia con base en datos de la Honorable Cámara de Diputados (www.diputados.gov.ar).

Los diputados noveles, en cambio, disminuyeron la cantidad de apoyos a los proyectos que alcanzaron fuerza de ley, en la medida en que el gobierno mostró altibajos. En suma, la influencia de la experticia parlamentaria es elevada en la titularidad y mayor en el copatrocinio de proyectos.

La composición de género acompaña los resultados generales que muestran al mismo tiempo un acercamiento positivo entre legisladoras y legisladores. Un aspecto destacable, durante el primer año, tiene que ver con la suma de firmantes en los casos en que una mujer fue titular de un proyecto de ley, y la media de legisladoras cofirmantes fue mayor. Cabe recordar que la composición inicial del grupo femenino dentro del bloque mostró un nivel considerable de experticia entre las legisladoras, pero una menor asignación a comisiones en relación con la de los legisladores. Este dato confirma el éxito legislativo conjunto de las legisladoras.

En este punto, la exposición de los resultados se emparenta con los rasgos individuales de los legisladores relacionados con la primera hipótesis. A continuación se muestra cómo la labor legislativa corresponde a los espacios ocupados en el sistema de comisiones. 
Cuadro 3. Producción legislativa por bloque político y comisión parlamentaria permanente (los resultados dentro del oficialismo se desagregan por fracción)

\begin{tabular}{|c|c|c|c|c|c|c|c|}
\hline $\begin{array}{l}\text { Presidencia } \\
\text { Comisión }\end{array}$ & $\begin{array}{l}\text { Fracción } \\
\text { oficialista }\end{array}$ & Comisión & $\begin{array}{l}\text { Integrantes } \\
\text { UCR }\end{array}$ & $\begin{array}{l}\text { Integrantes } \\
\text { FREPASO }\end{array}$ & $\begin{array}{l}\text { Leyes } \\
\text { Año } 2000\end{array}$ & $\begin{array}{l}\text { Leyes } \\
\text { Año } 2001\end{array}$ & $\begin{array}{c}\text { Total } \\
\text { Proyectos }\end{array}$ \\
\hline Alianza & FREPASO & $\begin{array}{l}\text { Asuntos Cooperativos, } \\
\text { Mutuales y Organizaciones } \\
\text { No Gubernamentales }\end{array}$ & 10 & 6 & & 3 & 3 \\
\hline Alianza & FREPASO & Ciencia y Tecnología & 12 & 10 & 1 & & 1 \\
\hline Alianza & FREPASO & Comercio & 10 & 8 & 1 & & 1 \\
\hline Alianza & FREPASO & $\begin{array}{l}\text { Derechos Humanos } \\
\text { y Gtías. }\end{array}$ & 12 & 8 & 1 & & 1 \\
\hline Alianza & FREPASO & $\begin{array}{l}\text { Población y Recursos } \\
\text { Humanos }\end{array}$ & 11 & 8 & & 1 & 1 \\
\hline Alianza & FREPASO & $\begin{array}{l}\text { Previsión y Seguridad } \\
\text { Social }\end{array}$ & 14 & 11 & 2 & 1 & 3 \\
\hline Alianza & UCR & $\begin{array}{l}\text { Asistencia Social y Salud } \\
\text { Pública }\end{array}$ & 16 & 3 & 6 & 2 & 8 \\
\hline Alianza & UCR & Asuntos Constitucionales & 18 & 6 & & 1 & 1 \\
\hline Alianza & UCR & $\begin{array}{l}\text { Comunicaciones e } \\
\text { Informática }\end{array}$ & 12 & 3 & 4 & 1 & 5 \\
\hline Alianza & UCR & Cultura & 13 & 5 & 2 & & 2 \\
\hline Alianza & UCR & Educación & 15 & 5 & 5 & 2 & 7 \\
\hline Alianza & UCR & Energía y Combustible & 12 & 4 & & 2 & 2 \\
\hline Alianza & UCR & Finanzas & 14 & 2 & 1 & 2 & 3 \\
\hline Alianza & UCR & $\begin{array}{l}\text { Intereses Marítimos, } \\
\text { Fluviales, Pesqueros } \\
\text { y Portuarios }\end{array}$ & 12 & 5 & & 2 & 2 \\
\hline Alianza & UCR & Justicia & 13 & 4 & 3 & 2 & 5 \\
\hline Alianza & UCR & Legislación General & 14 & 5 & 7 & & 7 \\
\hline Alianza & UCR & MERCOSUR & 16 & 5 & & 1 & 1 \\
\hline Alianza & UCR & Obras Públicas & 15 & 5 & 2 & & 2 \\
\hline Alianza & UCR & Presupuesto y Hacienda & 18 & 5 & 6 & 5 & 11 \\
\hline Alianza & UCR & $\begin{array}{l}\text { Relaciones Exteriores } \\
\text { y Culto }\end{array}$ & 15 & 5 & & 1 & 1 \\
\hline Alianza & UCR & Transportes & 9 & 4 & 1 & 1 & 2 \\
\hline Alianza & UCR & Turismo y Deportes & 16 & 4 & 3 & 2 & 5 \\
\hline Oposición & - & Agricultura y Ganadería & 16 & 4 & 4 & 1 & 5 \\
\hline Oposición & - & Defensa Nacional & 11 & 8 & 3 & 2 & 5 \\
\hline Oposición & - & Discapacidad & 7 & 5 & 4 & 1 & 5 \\
\hline Oposición & - & $\begin{array}{l}\text { Economías y Desarrollo } \\
\text { Regional }\end{array}$ & 13 & 11 & 1 & 1 & 2 \\
\hline Oposición & - & Familia, Mujer y Minoridad & 14 & 9 & 1 & & 1 \\
\hline Oposición & - & Legislación del Trabajo & 12 & 7 & 1 & & 1 \\
\hline Oposición & - & Legislación Penal & 10 & 5 & & 3 & 3 \\
\hline Oposición & - & Recursos Naturales & 13 & 9 & 2 & 3 & 5 \\
\hline Totales & & & & & 61 & 40 & 101 \\
\hline
\end{tabular}

De acuerdo con los resultados para ambos periodos, la Alianza logró sancionar 74 proyectos derivados de 22 comisiones a cargo del oficialismo. 
La composición de grupo en comisiones, junto con el esquema de cargos, presentada en el apartado anterior, observa un claro impacto en la cohesión del grupo y la producción parlamentaria exitosa. Las 64 leyes que el radicalismo impulsó fueron respaldadas por comisiones con un alto número de integrantes del partido. Cabe decir que los espacios en la estructura de cargos tuvieron el mismo impacto en la tarea legislativa, inclinando la balanza hacia el oficialismo y, dentro de la Alianza, hacia la UCR.

Los resultados expuestos confirman la hipótesis 1, destacándose tres aspectos centrales para explicar la cohesión: la pertenencia al distrito de la Provincia de Buenos Aires, la experiencia legislativa, y la distribución de la Alianza en la Cámara, aspectos que permiten relacionar en forma directa los resultados del trabajo legislativo con la composición que tuvo el grupo en funciones.

$\mathrm{Al}$ inicio de este apartado se hizo referencia a las áreas exitosas en la producción de leyes y a las comisiones participantes. Las comisiones estratégicas (Presupuesto y Hacienda, Asuntos Constitucionales, entre otras) contabilizaron un número bajo de proyectos exitosos respecto del total sancionado. Estas instituciones cargan con la incidencia de las iniciativas del Poder Ejecutivo pero son firmadas e ingresadas por legisladores. Vale decir que en aquellos temas donde el nivel de conflicto resultó menor, también existió mayor posibilidad de éxito.

Aquí el trabajo involucra la condición oficialista del bloque y suma a la observación de la tarea legislativa las iniciativas inconclusas, lo cual permite guiar el desarrollo del trabajo a la segunda hipótesis.

\section{H2. La práctica cooperante en el oficialismo: cambios y continuidades}

El bloque de la Alianza resulta a la vez un caso oficialista, expuesto a las influencias de su gobierno en ejercicio. Los vaivenes políticos, que tienen incidencia en todos los niveles de gobierno, influyen en el copatrocinio a lo largo del tiempo. ¿Quién se acercó a quién? Ésta es la pregunta central que guía la observación en torno a la integración de diputados y diputadas en la labor parlamentaria dentro y fuera de los límites del bloque.

Los sucesos políticos identificados como influyentes en el curso del apoyo de firmas fueron recolectados de acuerdo con el Diario de Sesiones y el respaldo periodístico.

En el primer año parlamentario, la iniciativa y sanción de la Ley Núm. 25250 de Reforma Laboral, sancionada en mayo del año 2000, se convirtió en la primera ley y el primer quiebre para el bloque, que derivó en los actos de cohecho denunciados meses después en el Senado Nacional y en la renuncia posterior del vicepresidente Carlos “Chacho” Álvarez. Esto influyó negativamente en la 
unidad del bloque y en los diputados que respondían a esta fracción. Hacia fines de aquel año tuvieron lugar varios sucesos, como el primer recambio de ministros dentro del gabinete y un avance del radicalismo en los espacios frepasistas. En el marco de las sesiones extraordinarias acontece el último hecho influyente: la operación de megacanje de la deuda externa.

En el segundo año, la asistencia a la Cámara resultó mucho menor en virtud de que se trataba de un año electoral y con vistas a la renovación parlamentaria (2001-2003). En particular, el bloque oficial sufrió el impacto político del segundo cambio de gabinete (con el ingreso de Domingo Cavallo), y la conformación de los bloques disidentes, detallados en el apartado anterior. La convocatoria a la unidad nacional por parte del presidente, y los resultados de las elecciones legislativas en octubre de 2001, resumen el segundo y último periodo de gobierno considerado para este análisis.

La participación de los legisladores en los proyectos se presenta en dos instancias: a) entre oficialistas, puertas adentro, y b) junto con la disidencia y la oposición para lograr la observación entre bloques.

\section{El trabajo conjunto entre fracciones de la Alianza}

El bloque oficialista, visto desde el trabajo conjunto, obtuvo los resultados que muestra el cuadro 4 .

Cuadro 4. Legislación sancionada del oficialismo por fracción desagregada por año parlamentario

\begin{tabular}{l|c|ccc}
\hline \multirow{2}{*}{ Periodo parlamentario } & Leyes sancionadas & \multicolumn{2}{c}{ Trabajo dentro del bloque Alianza } \\
\cline { 2 - 5 } & Oficialismo & Único autor & Múltiples integrantes & $\begin{array}{c}\text { Fracciones en } \\
\text { conjunto* }\end{array}$ \\
\hline Fracción UCR & 16 & 5 & 11 & 0 \\
Fracción FREPASO & 5 & 1 & 1 & 3 \\
\hline Año Parlamentario 118 & 21 & 6 & 12 & 3 \\
\hline Fracción UCR & 6 & 3 & 2 & 1 \\
Fracción FREPASO & 4 & 1 & 5 & 1 \\
\hline Año parlamentario 119 & 10 & 4 & 17 & 4 \\
\hline Total & 31 & 10 & 3 \\
\hline * La columna Fracción en conjunto asigna valor a quien haya encabezado el proyecto parlamentario.
\end{tabular}

Al inicio de este artículo se argumentó que la distribución de los integrantes de comisiones y la asignación de jefaturas favorables a la fracción radical dieron 
como resultado una condición adversa al trabajo entre pares. La observación de los resultados, en relación con la práctica cooperante, expone una conclusión contundente: la Alianza, coincidente con la evolución de la Cámara, alentó el trabajo conjunto. Sin embargo, en el plano del éxito parlamentario, las fracciones integrantes tuvieron escasos registros conjuntos, los cuales fueron encabezados en mayor medida por radicales, con acompañamiento de radicales y pocos frepasistas. Este dato conduce al escrito a explorar qué permitió lograr la cooperación entre diputados.

\section{El camino de la cooperación puertas adentro}

$\mathrm{Al}$ margen de que un proyecto logre el éxito parlamentario, los registros firmantes permiten analizar en qué forma se gesta la cooperación entre diputados. Aquí, las iniciativas inconclusas aportan información, en ellas se registra un número mayor de proyectos conjuntos. Durante el segundo año parlamentario 119, la característica compartida por los aliancistas fue su pertenencia al sector menos alineado al Poder Ejecutivo y su escasa experiencia parlamentaria, donde la presentación de iniciativas paralelas resultó un canal de expresión de disidencias. Esta tendencia se consolidó luego del segundo cambio de gabinete, en abril de 2001, cuando $50 \%$ de los legisladores que colaboraron con los diputados disidentes del bloque (en total 22) no contaba con experiencia parlamentaria anterior y eran diputados sin jerarquía política en el bloque legislativo.

Los resultados, vistos por fracción, demuestran una tendencia bien marcada: en la medida que el bloque inicial se subdividió en cuatro bloques, la presencia de diputados radicales en las firmas de proyectos impulsados por diputados disidentes decreció significativamente. De un total de 91 diputados radicales, sólo nueve apoyaron iniciativas tanto del ARI como del FC. Éste es un dato importante ya que, en realidad, el grupo de legisladores radicales que mantuvo la continuidad en materia de trabajo parlamentario con sus nuevos opositores fue reducido. La conducción del bloque oficial para ambas fracciones respalda esta tendencia. Horacio Pernasetti, de la fracción radical, no acompañó iniciativa disidente alguna, y los proyectos registrados con su autoría fueron acompañados únicamente por radicales. Darío Alessandro, de la fracción frepasista, sólo en dos oportunidades firmó proyectos para la disidencia, y aun así, en los proyectos de su autoría no intervinieron diputados disidentes.

Dentro de la fracción frepasista, el escenario político en la Cámara durante el segundo año favoreció la cooperación. En la gráfica 5 se registra el avance del Frepaso en la Cámara con las iniciativas presentadas y los proyectos conjuntos. 
Gráfica 5. Iniciativas parlamentarias por bloque parlamentario desagregado por año parlamentario

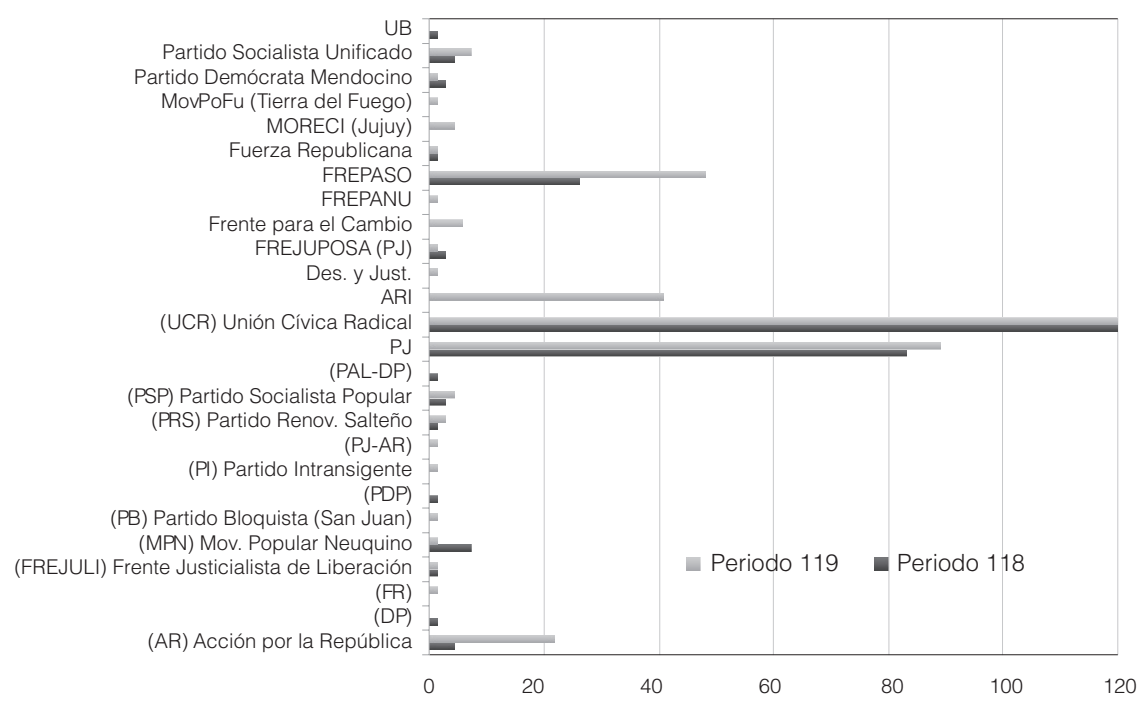

Fuente: Elaboración propia con base en datos de la Honorable Cámara de Diputados (www.diputados.gov.ar).

Este aspecto está relacionado con el comportamiento asumido como bloque dentro del bloque donde se autoconvocó, sin presencia de las autoridades parlamentarias, y alejado del partido político. En efecto, la fracción acompañó 56 iniciativas durante ambos años. El primer año sostuvo 17 proyectos y en el segundo sumó 39 respaldos a iniciativas. Las rupturas de bloque se produjeron por diferencias con el oficialismo en el gobierno y por reacción al núcleo fuerte del oficialismo dentro del bloque. El Frepaso, en este contexto, logró un mayor grado de integración en la tarea legislativa al convertirse en un nexo entre los parlamentarios que se fueron del bloque y los diputados que continuaron siendo oficialistas. La tarea legislativa de la disidencia expuesta a continuación sostiene este argumento.

\section{El trabajo conjunto puertas afuera: los nuevos bloques y el PJ}

A pesar de los realineamientos dentro de la Alianza, la media de firmantes de la Cámara no mostró una variación significativa entre ambos periodos. El cambio, entonces, se relaciona con los participantes en los proyectos entre ambos periodos legislativos. En el cuadro 5, se observa la performance de los nuevos bloques (ARI y FC), en su trabajo conjunto. 
Cuadro 5. Bloques disidentes (ARI y FC): participación en proyectos parlamentarios oficialistas y opositores (periodo parlamentario 2001)

\begin{tabular}{|c|c|c|c|c|c|}
\hline \multirow{3}{*}{ Nuevo bloque (integrantes) } & \multirow{3}{*}{$\begin{array}{l}\text { Fracción } \\
\text { originaria }\end{array}$} & \multicolumn{4}{|c|}{$\begin{array}{l}\text { Participación en proyectos parlamentarios } \\
\text { (titular o cofirmante) }\end{array}$} \\
\hline & & \multicolumn{2}{|c|}{ Alianza } & \multirow{2}{*}{$\begin{array}{l}\text { Frente para el } \\
\text { Cambio }\end{array}$} & \multirow{2}{*}{$\begin{array}{c}\text { Primera } \\
\text { oposición (PJ) }\end{array}$} \\
\hline & & $U C R$ & FREPASO & & \\
\hline \multicolumn{6}{|l|}{$\begin{array}{l}\text { Argentinos por una República } \\
\text { de Iguales }\end{array}$} \\
\hline Carrió, Elisa* & (UCR) & 18 & 17 & 1 & 7 \\
\hline Bravo, Alfredo & (PS-FREPASO) & 43 & 14 & 17 & 14 \\
\hline Rivas, Jorge & (PS-FREPASO) & 4 & 23 & 11 & 7 \\
\hline Polino, Hector & (PS-FREPASO) & 9 & 31 & 10 & 9 \\
\hline Cantero, Fernando A. & (UCR) & 2 & 17 & 4 & 3 \\
\hline \multicolumn{6}{|l|}{ Frente para el Cambio } \\
\hline Torres Molina, Ramón Horacio* & (FREPASO) & 9 & 12 & 8 & 4 \\
\hline Villalba, Alfredo & (FREPASO) & 9 & 21 & 11 & 7 \\
\hline Cardesa, Enrique Gustavo & (FREPASO) & 7 & 14 & 9 & 8 \\
\hline Castro, Alicia & (FREPASO) & 4 & 7 & 6 & 6 \\
\hline
\end{tabular}

* Jefe de bloque.

Fuente: Elaboración propia con base en datos de la Honorable Cámara de Diputados (www.diputados.gov.ar)

En relación con el trabajo conjunto en la disidencia, los datos muestran que el ARI tuvo un grado de copatrocinio mayor que el FC y en calidad de nexo con la Alianza a través del Frepaso. El FC se asoció en menos oportunidades con diputados oficialistas. De acuerdo con los registros, que contabilizan a los legisladores del Frepaso que continuaron en bloque con el ARI, se confirma su condición de canal para la cooperación dentro de la Cámara.

La particularidad del FC es que todos sus integrantes provenían del Frepaso, razón por la cual se podría suponer, a priori, que el nivel de iniciativa conjunta con el Frepaso resultaría bajo. Sin embargo, en todos los casos, la mayor cantidad de iniciativas fue firmada o acompañada con su fracción de origen (Frepaso). La diputada más distante al radicalismo resultó ser Alicia Castro, y el más cercano al socio menor de la Alianza fue Alfredo Villalba.

Afortunadamente, en todo bloque existe un ala intransigente y otra dialoguista hacia el oficialismo en la Cámara, que permite, ante los cambios, mantener la continuidad y servir de canal para el funcionamiento del sistema de bloques; en esto, el caso paradigmático para la Alianza resultó la ley referida al Instituto de la Yerba Mate, proyecto sancionado en la última sesión como oficialista (octubre de 2001), en el que oficialistas, disidentes y opositores dieron su voto favorable.

La interacción con el PJ, que ofició de primera oposición en aquel momento, merece una nota especial: entre el pj y la Alianza Parlamentaria, el oficialismo integró a sus proyectos un acompañamiento mayor de peronistas, en 
comparación con las firmas que dieron los oficialistas a los proyectos del PJ. En 2001, esta tendencia se revierte y la oposición aumenta su iniciativa parlamentaria tanto en cantidad de leyes como de cofirmantes a sus iniciativas. Esto es ocasionado por la reunificación de las fracciones del pu dentro de la Cámara y las perspectivas electorales de renovación parlamentaria, en relación con su comportamiento histórico, el cual mantiene una unidad simbólica y funciona en los hechos como un grupo de subbloques diferenciados que responden a los referentes partidarios (María Barón, 2001).

Los resultados expuestos confirman la hipótesis 2 , en la cual se verifica que el curso de la cooperación tuvo cambios y continuidades al mismo tiempo, en su condición de oficialista. La alineación con el gobierno y las rupturas de bloque alejaron al núcleo cercano al gobierno del resto del bloque abriendo paso a una zona de cooperación entre legisladores oficialistas y opositores, a través de los frepasistas. Así, se relacionan en forma directa los resultados del trabajo legislativo con la condición de oficialistas de los legisladores.

\section{Lecciones aprendidas con la Alianza}

Los resultados de ambas hipótesis permiten analizar el copatrocinio en un nivel de profundidad mayor al acompańamiento taxativo del proyecto, y dar respuesta a los objetivos propuestos en el trabajo: las motivaciones para colaborar y las características que adoptó esta colaboración en un caso de coalición formal en el país.

Las condiciones para colaborar, según lo expuesto en estas páginas, estuvieron mediadas por el grupo y también por el curso político. Ahora, ¿qué motivó a los legisladores a acercarse y apoyar a un compañero de banca? La exploración entre los legisladores demuestra que la participación en una iniciativa podría deberse a tantas causas como proyectos llegaran a presentarse. En este punto, las fuentes incluidas identificaron las siguientes motivaciones:

1. La unificación de proyectos expuestos por diputados o grupos de diputados cuya conjunción resulta superadora de las partes;

2. La integración al grupo parlamentario por parte de diputados noveles;

3. El prestigio que supone la incorporación de un legislador con experiencia (o referente en el tema dentro de la Cámara), el cual constituye un aval a la iniciativa;

4. El método de competencia entre legisladores y/o entre bloques;

5. Una herramienta de respuesta parlamentaria a la acción política del Poder Ejecutivo; 
6. Un canal al servicio de los jefes de bloque para encauzar las tensiones entre sus parlamentarios pertenecientes a un bloque o interbloque;

7. La instalación del tema en los medios periodísticos, lo cual eleva la publicidad del proyecto y estimula al acompańamiento de la iniciativa por su nivel mediático;

8. Los compromisos asumidos con los distritos de origen por parte de legisladores de distintos bloques (ya sea en leyes de forma como normas de importancia);

9. El tema presupuestario (caso impuestos aduaneros) que unifica intereses provinciales, $y$

10. Causas históricas comunes, sociales (derechos humanos o los golpes de estado) y/o humanitarias (discapacidad).

La propuesta de legislación en muchos casos es harto compleja, y su instancia de elaboración inicial de texto y promoción se ubica antes de presentar el trámite parlamentario, en el área de la relación social y humana entre legisladores, junto con actores políticos y sociales externos a la Cámara. Su motivación tiene respuesta en virtud de que, desde el retorno a la democracia, el Poder Legislativo ha capitalizado un aprendizaje parlamentario en cuanto a la forma de impulsar el trabajo legislativo y un cambio cultural de trabajo.

Esta transformación ha redefinido el proyecto de legislación en un fin parlamentario y un medio político al mismo tiempo, y se pone de relieve en la segunda hipótesis acerca de la influencia del curso político en la colaboración. Los resultados expuestos se inscriben en una línea desarrollada dentro del estudio del copatrocinio, de la cual destacamos aquí a Yang Zhang et al. (2006). Mediante el concepto de modularidad de las redes, estos investigadores estudian la variación de la polarización política en la Cámara de Estados Unidos (1995-1996), en función de los cambios en la composición de las redes copatrocinantes en el tiempo.

En la coalición aliancista, la observación de los resultados para ambos periodos identifica al distrito y al partido como variables explicativas, coincidentes con los resultados de la investigación a cargo de Calvo, y Leiras (2011), a lo que es necesario sumar la experiencia de los titulares de las bancas, la distribución del bloque en la Cámara y el contexto político ocurrido entre 2000 y 2001, para poder fundamentar realmente el curso de la cooperación oficialista en este caso.

De acuerdo con la hipótesis de la socialización (De Miguel, 2005: 41), cuanto mayor sea la trayectoria política del diputado, mayor será su grado de cohesión. La relación entre parlamentarios oficialistas y/o opositores se acrecentaron con la antigüedad, la cercanía en las comisiones y el conocimiento mutuo que se consigue sólo con la militancia, el tiempo y los distintos escenarios que tuvieron lugar en la Cámara. En efecto, el respeto por la trayectoria partidaria 
resultó un argumento habitual en las intervenciones del recinto, aun en los momentos de mayor tensión.

La relación entre esta premisa y el caso estudiado requiere la distinción entre fracciones: el radicalismo demostró mayores rasgos de socialización que el Frepaso, en virtud del grado de acercamiento mayor entre sus integrantes, ya sea por su historia partidaria, el ascenso del grupo federal vis-à-vis con el núcleo Capital/ Buenos Aires, su pensamiento orgánico y los lazos con diputados opositores (PJ) con quienes compartieron un número similar de mandatos en la Cámara.

En el Frepaso, la elevada libertad de conciencia entre sus integrantes y la escasa relación con sus pares radicales en la arena parlamentaria consiguió — sólo a partir del distanciamiento del gobierno- elevar su nivel de integración en la Cámara, al convertirse en un puente entre bloques, de acuerdo con el aumento de frentistas en los registros legislativos.

La Alianza por el Trabajo, la Justicia y la Educación resultó un caso atípico en la política argentina, que heredó el aprendizaje adquirido en dos décadas de democracia dentro de la Cámara y se conformó, en su mayoría, con legisladores de trayectoria en un partido y/o en la legislatura, pero que, al asumir sus funciones, cada fracción se comportó como un bloque en sí mismo; por este motivo, este escrito concluye que el trabajo conjunto resulta, en este tramo de la legislatura, un mérito del sistema de bloques en conjunto.

\section{Referencias}

Alemán, Eduardo, y Ernesto Calvo, 2013, "Explaining Policy Ties in the Argentine and Chilean Congresses: A Network Analysis of Bill Initiation Data”, Political Studies, vol. 61, núm. 2, junio, pp. 356-377.

Alemán, Eduardo et al., 2009, "Comparing Cosponsorship and Roll-Call Ideal Points", Legislative Studies Quarterly, vol. 34, núm. 1.

Barón, María, 2003, El Poder Legislativo nacional, Buenos Aires, Centro de Implementación de Políticas Públicas para la equidad y el crecimiento (CIPPEC).

Bernhard, William T., y Tracy Sulkin, 2009, Cosponsorship and Coalition-Building in the U.S. House, APSA 2009 Toronto Meeting Paper, disponible en <http://ssrn.com/abstract=1452258>, consultado el 9 de octubre de 2012.

Bowler, Shaun, David M. Farrell, y Richard S. Katz, 1999, Party Discipline and Parliamentary Government, Ohio, Ohio State University Press. 
Calvo, Ernesto, y Marcelo Leiras, 2011, “The Nationalization of Legislative Collaboration: Territory, Partisanship, and Policymaking in Argentina”, Documento de Trabajo 06/2011, Instituto Universitario de Iberoamérica, Universidad de Salamanca.

Casar, María Amparo, 2000, "Coaliciones y cohesión partidista en un Congreso sin mayoría: la Cámara de Diputados de México, 1997-1999”, Política y Gobierno, vol. VII, núm. 1, primer semestre.

Colombo, Carlos, 2000, Antecedentes parlamentarios, Buenos Aires, Ediciones La Ley (tomo 2000B).

Cox, Gary, y Scott Morgenstern, 2002, "Epilogue: Latin America’s Reactive Assemblies and Proactive Presidents", en Scott Morgenstern y Benito Nacif (eds.), Legislative Politics in Latin America, Cambridge, Cambridge University Press.

De Luca, Miguel, Mark P. Jones, y María Inés Tula, 2002, "Back Rooms or Ballot Boxes? Candidate Nomination in Argentina”, Comparative Political Studies, vol. 35, núm. 4.

De Miguel, Roberto, 2005, Comunicación y lealtad parlamentaria, Madrid, Editorial Club Universitario.

Dirección de Información Parlamentaria, 2005, "Bloques Parlamentarios 2000-2005”, Documentos de Trabajo núms. 1201 y 1372, Honorable Cámara de Diputados de la Nación.

Fowler, James, 2006, “Connecting the Congress: A Study of Cosponsorship Networks", Political Analisys, núm. 14, disponible en <http://jhfowler.ucsd.edu/best_connected_congressperson. pdf>, consultado el 15 de octubre de 2012.

González Tule, Luis Antonio, 2007, “Cohesión partidista en la Cámara de Diputados en México: el caso del PRI, el PAN y el PRD (1997-2006), Revista de Investigaciones Politicas y Sociológicas, vol. 6, núm. 2.

Hawkins, Kirk, y Scott Morgenstern, 2003, "Cohesion of Legislators in Latin America: Patterns and Explanations”, Duke Working Paper, Durham, Duke University.

Hazan, Reuven, 2003, "Does Cohesion Equal Discipline? Toward a Conceptual Delineation", The Journal of Legislative Studies, núm. 29.

Jones, Mark, 2002, "Explaning the High Level Discipline in the Argentine Congress", en Scott Morgenstern y Benito Nacif (eds.), Legislative Politics in Latin America, Cambridge, Cambridge University Press. 
Jones, Mark, Sebastian Saiegh, Pablo Spiller, y Mariano Tommasi, 2002, “Amateur LegislatorsProfesional Politicians: The consequences of Party-Centered Electoral Rules in a Federal System", American Journal of Political Science, vol. 46, núm. 3.

Mustapic, Ana María, 2000, "Oficialistas y diputados: Las relaciones Ejecutivo-Legislativo en la Argentina”, Desarrollo Económico, vol. 39, núm. 156.

Ollier, María Matilde, 2001, Las coaliciones políticas en la Argentina: el caso de la Alianza, Buenos Aires, Fondo de Cultura Económica.

Ostrom, Elinor, y James Walker, 1996, "Neither Markets Nor States: Linking Transformation Processes in Collective Action Arenas", en Dennis C. Mueller, Perspectives on Public Choice. A Handbook, Cambridge Books Online, disponible en <http://dx.doi.org/10.1017/ CBO9780511664458>, consultado el 10 de octubre 2012.

Owens, John, 2003, "Explaning Party Cohesion and discipline in Democratic Legislatures: Purposiveness and Contexts", The Journal of Legislative Studies, vol. 9, núm 4.

Ozbudun, Erzun, 1970, Party Cohesión in Western Democracies. A Causal analysis, Beverly Hills, Sage.

Tsebelis, George, 1995, "Decision Making in Political Systems: Veto Players in Presidentialism, Parlamentarism, Multicameralism and Multiparties", British Journal of Political Sciences, vol. 25 , núm. 3 .

Zhang, Yan et al., 2006, "Community structure in Congressional Cosponsorship Networks", disponible en <http://jhfowler.ucsd.edu/community_structure.pdf>, consultado el 30 de septiembre de 2012.

Recibido el 22 de agosto de 2011. Aceptado el 30 de agosto de 2014. 